\title{
On the threshold of better futures
}

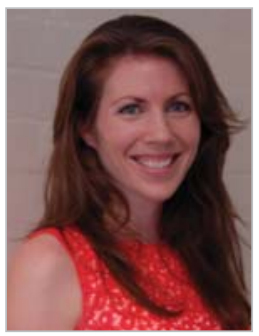

Christine Gee Deputy Editor mja@mja.com.au

doi: 10.5694/mjal4.c0602 current fee-for-service model creates inefficiencies and is likely to generate increased costs with increasing numbers of providers. There is also considerable inequity around access, particularly for specialist services. The authors conclude that understanding the effectiveness and cost-effectiveness of interventions funded by Medicare will be crucial to its success in meeting rising demand.

In another birthday milestone, Australians who turn 18 years of age avail themselves not only of the right to vote but of the right to buy alcohol, should they wish to do so. This legal right is anticipated eagerly by many underage teenagers in Australia (and many do not wait until they turn 18). But is it safe? Toumbourou and colleagues (page 568) argue that there is ample evidence to support raising the legal drinking age to 21 . They contend that, at 18 , young people are more vulnerable to alcohol-related harms than their 21-yearold counterparts. They also cite data suggesting that

increasing the legal drinking age would reduce alcohol-related traffic crash injuries. Although the proposal is controversial, they believe that commonly raised objections can be refuted. Another measure to promote safe drinking is also discussed in this issue. A qualitative study of Western Australians aged 18-21 years by Pettigrew and colleagues (page 577) suggests that a "responsible drinking" campaign by DrinkWise may actually have had the opposite effect. Some of the young people sampled in the study reported that the advertisement may have encouraged them to drink more, rather than less.

For many people with cancer, each anniversary of their diagnosis is an important survival milestone a cause for celebration and a time to reflect on what lies ahead. Yu and colleagues (page 586) present their findings on prostate cancer survival in New South Wales. In their report, they expand on an earlier study by accounting for stage at diagnosis, and investigate whether rural-urban disparities in mortality have improved. When adjusted for five prognostic factors, their data suggest that patients with a rural place of residence still have a higher risk of death. On a positive note, they found that overall survival increased during the study period, from $57.5 \%$ in $1992-1996$ to $83.7 \%$ in 2002-2007.

Arguably, all of us should view a birthday as a cause for happy recognition. Here at the Journal, perhaps we could be forgiven for raising a glass in honour of reaching 100 !

\section{Mentoring makes a comeback}

\section{Cate Swannell \\ Careers Editor cswannell@mja.com.au}

A decade ago, then editor of the MJA Martin Van Der Weyden observed that in an increasingly time-poor environment the art of mentoring medical students was slipping by the wayside. Fast forward to 2014 and mentoring is once again part of the zeitgeist. Mentoring has long been considered beneficial from an academic or career perspective, but there is increasing recognition that it may also benefit the psychological outlook of students, interns and doctors-in-training in particular. beyondblue's 2013 findings that Australian doctors and medical students suffer high rates of burnout, suicidal thoughts and psychological stress compared with the general population have been a wake-up call.
In the past fortnight, the

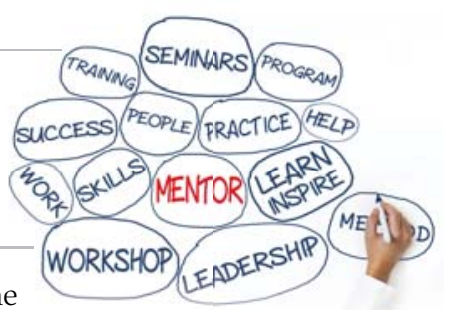
Australian Medical Students' Association has appointed its first national mentoring coordinator, and, in March, the NSW branch of the Australian Medical Association launched the latest of a growing number of AMAsponsored intern-doctor, student-doctor and junior doctor-senior doctor mentorship programs around the country. At the same time, the Australasian College for Emergency Medicine and other colleges have begun a host of formal programs to recruit and train mentors (page C1).

Dr Linda Mann has been a hero to a generation of female general practitioners since she set up her own practice in 1987. Read her story (page C4). 